\title{
Flavonoid content, free radical scavenging and increase in xanthine oxidase inhibitory activity in Galgeun-tang following fermentation with Lactobacillus plantarum
}

\author{
DONG-SEON KIM, YOUNG RAN UM and JIN YEUL MA
}

KM-Based Herbal Drug Development Group, Korea Institute of Oriental Medicine, Daejeon 305-811, Republic of Korea

Received January 26, 2014; Accepted March 28, 2014

DOI: $10.3892 / \mathrm{mmr} .2014 .2487$

\begin{abstract}
Galgeun-tang (GT) prior to and following fermentation with Lactobacillus plantarum was analyzed to determine the total polyphenol and flavonoid contents and the antioxidant activity. GT, fermented GT (FGT) and their three solvent-partitioned fractions, which were prepared by successive partitioning with ethyl acetate (EtOAc), butanol $(\mathrm{BuOH})$ and water, were evaluated for total polyphenol and flavonoid contents, 2,2-diphenyl-1-picrylhydrazyl (DPPH) radical scavenging activity and xanthine oxidase (XO) inhibitory activity. Following fermentation, the total polyphenol content only increased slightly; however, the flavonoid content increased by $24.3 \%$. The radical scavenging activity increased from 22.4 to $27.5 \%$ and the XO inhibitory activity increased from 20.2 to $62.4 \%$ at $500 \mu \mathrm{g} / \mathrm{ml}$. The EtOAc fraction among the solvent-partitioned fractions demonstrated the highest total polyphenol and flavonoid contents, radical scavenging activities and XO inhibitory activity, and the quantity also markedly increased following fermentation.
\end{abstract}

\section{Introduction}

Galgeun-tang (GT) is a traditional herbal decoction used in the treatment of cold, fever and muscular pain and consists of Puerariae Radix, Ephedrae Herba, Zizyphi Fructus, Cinnamomi Cortex, Paeniae Radix, Glycyrrhizae Radix and Zingiberis Rhizoma at a ratio of 8:4:4:3:3:2:1 (1). The fermentation of the herbs is generally performed using probiotics, including Lactobacillus sp. and Bifidobacterium sp., which transform the herbal components to their aglycones, amino acids, vitamins or organic acids (2-5). During fermentation of the herbs, certain glycosides are deglycosylated into small,

Correspondence to: Dr Jin Yeul Ma, KM-Based Herbal Drug Development Group, Korea Institute of Oriental Medicine, 1672 Yuseong-daero, Yuseong-gu, Daejeon, 305-811, Republic of Korea

E-mail: jyma@kiom.re.kr

Key words: Galgeun-tang, fermentation, antioxidant activity, xanthine oxidase inhibitor hydrophobic molecules that may be more efficacious than conventional herbal medicines due to the increased absorption and bioavailability of the active components in the body (4-7). Polyphenols are alcohols containing two or more benzene rings that each have at least one hydroxyl group attached and can range from simple molecules (phenolic acids, phenylpropanoids and flavonoids) to highly polymerized compounds (lignins, melanins and tannins), with flavonoids representing the most common and widely distributed subgroups (8). These compounds have been reported to have antioxidant activity; however, flavonoids in particular exhibit a wide range of biological effects, including antibacterial, anti-inflammatory, antiallergic, hepatoprotective, antithrombotic, antiviral, anticarcinogenic and vasodilatory activities, in addition to their antioxidant activities $(9,10)$. Indeed, the majority of these biological functions have been attributed to their free radical scavenging and antioxidant activity (11). Oxidative damage appears to be associated with the etiology of cardiovascular disease, diabetes mellitus, gastric ulcers, arthritis, cancer and inflammation $(12,13)$.

Xanthine oxidase $(\mathrm{XO})$ catalyzes the metabolization of hypoxanthine and xanthine to uric acid, and its overproduction results in gout (14). Furthermore, hyperuricemia is demonstrated to be correlated with cardiovascular events, including stroke and coronary heart disease $(15,16)$. This explains why inhibition of this enzyme is an ideal strategy for reducing the serum level of uric acid.

Based on these studies, the present study therefore attempted fermentation to increase the biological efficacy of GT and evaluated the total polyphenol and flavonoid contents, 2,2-diphenyl-1-picrylhydrazyl (DPPH) free radical scavenging activity and $\mathrm{XO}$ inhibitory activity.

\section{Materials and methods}

Preparation of GT and FGT. Puerariae Radix (Korea), Ephedra Herb (China), Zingiberis Rhizoma (Korea), Zizyphi Fructus (Korea), Cinnamomi Cortex (Vietnam), Paeniae Radix (Korea) and Glycyrrhizae Radix (China) were purchased from the Korea Medicine Herbs Association (Yeongcheon, Korea). All voucher specimens were deposited in the herbal bank of Herbal Medicine Improvement Research Center, Korea Institute of Oriental Medicine (Daejeon, Korea).

The mixture of medicinal herbs $(2,500 \mathrm{~g})$, Puerariae Radix (800 g), Ephedra Herb (400 g), Zizyphi Fructus 
(400 g), Cinnamomi Cortex (300 g), Paeoniae Radix (300 g), Glycyrrhizae Radix (200 g) and Zingiberis Rhizoma (100 g) was soaked in water $(33 \mathrm{l})$ for $1 \mathrm{~h}$ and then boiled for $3 \mathrm{~h}$. Following cooling to room temperature, the extract solution was filtered using standard testing sieves $(150 \mu \mathrm{m}$; Retsch, Haan, Germany) to yield GT (28.3 1). A portion (10 1) of the decoction was freeze-dried, yielding the GT extract (261.5 g; estimated extraction yield from herb materials: $29.61 \%$ ) and stored in desiccators at $4^{\circ} \mathrm{C}$ until use.

For the preparation of FGT, GT (10 l) was adjusted to pH 8.0 using $1 \mathrm{M} \mathrm{NaOH}$ and was then sterilized in an autoclave at $121^{\circ} \mathrm{C}$ for $15 \mathrm{~min}$ and cooled to $37^{\circ} \mathrm{C}$. The GT was fermented by inoculation of $10 \mathrm{ml}$ of Lactobacillus plantarum $\left(1 \times 10^{8} \mathrm{CFU} / \mathrm{ml}\right)$. Pure cultures of Lactobacillus plantarum (KFRI 144) were obtained from the Korea Food Research Institute (Songnam-si, Korea). Prior to experimental use, the bacterial strain was incubated in MRS medium (Difco ${ }^{\mathrm{TM}}$ Lactobacilli MRS Broth; Becton-Dickinson, Hunt Valley, MD, USA) at $37^{\circ} \mathrm{C}$ overnight. GT was inoculated with the bacterial strain, fermented at $37^{\circ} \mathrm{C}$ for $48 \mathrm{~h}$ and then filtered through a $60 \mu \mathrm{m}$ nylon net filter (Millipore, Billerica, MA, USA). The fermented decoction was freeze-dried, yielding the FGT extract $(260.1 \mathrm{~g}$; estimated extraction yield from herb materials: $29.44 \%$ ) and stored in desiccators at $4^{\circ} \mathrm{C}$ until use.

Solvent fractionation. A total of $26.0 \mathrm{~g}$ of GT or FGT was dissolved in 11 water each and sequentially partitioned with equal volumes of ethyl acetate (EtOAc) and butanol $(\mathrm{BuOH})$. All the fractions were evaporated to dryness and freeze-dried, yielding EtOAc (GT, $0.927 \mathrm{~g}$; FGT, $1.752 \mathrm{~g}$ ), BuOH (GT, 3.820 g; FGT, $4.541 \mathrm{~g}$ ) and water (GT, $19.103 \mathrm{~g}$; FGT, $14.921 \mathrm{~g}$ )-soluble fractions.

Determination of total polyphenol and flavonoid content. The total polyphenol content of the samples was determined by the Folin-Ciocalteu method (17). The appropriate dilutions of samples $(2 \mathrm{ml})$ were oxidized with Folin-Ciocalteu's reagent ( $2 \mathrm{ml}$; Sigma, St. Louis, MO, USA) for $3 \mathrm{~min}$. The reaction was neutralized with $10 \%$ sodium carbonate solution $(2 \mathrm{ml})$. The contents in the tubes were thoroughly mixed and allowed to stand at ambient temperature for $1 \mathrm{~h}$ until the characteristic blue color developed. The absorbance of the clear supernatant was measured at $700 \mathrm{~nm}$ using a spectrophotometer. The total polyphenol content in each sample was calculated based on a standard curve prepared using tannic acid (Sigma) and expressed as $\mu \mathrm{g}$ of tannic acid equivalent per mg of sample.

The total flavonoid content of the samples was determined with aluminum nitrate using quercetin (Sigma) as the standard (18). Each $1 \mathrm{mg}$ aliquot of the samples was added to $1 \mathrm{ml}$ $80 \%$ ethanol. A $0.5 \mathrm{ml}$ aliquot was added to each test tube containing $0.1 \mathrm{ml} 10 \%$ aluminum nitrate, $0.1 \mathrm{ml} 1 \mathrm{M}$ potassium acetate and $4.3 \mathrm{ml} 80 \%$ ethanol. The absorbance of the supernatant was measured at $415 \mathrm{~nm}$ following incubation at room temperature for $40 \mathrm{~min}$. The total flavonoid content in the samples was determined as $\mu \mathrm{g}$ quercetin equivalent from a standard quercetin graph.

Free radical scavenging assay and activity-guided fractionation. The free radical scavenging activity of the samples was measured by employing the 2,2-diphenyl-1-picrylhydrazyl radical (DPPH; Wako Pure Chemical Industries, Ltd., Osaka, Japan) assay (19). A DPPH solution in ethanol and dimethylsulfoxide (DMSO) was prepared and $900 \mu$ l of this solution was added to $100 \mu 1$ of each sample dissolved in ethanol $(500 \mu \mathrm{g} / \mathrm{ml})$.

The mixture was agitated and then allowed to stand at room temperature for $10 \mathrm{~min}$. The absorbance was subsequently measured at $518 \mathrm{~nm}$ using a spectrophotometer. The percentage of scavenging activity at different concentrations was determined and compared with that of L-ascorbic acid $(25 \mu \mathrm{g} / \mathrm{ml})$, which was used as the standard. The inhibition of the DPPH radical scavenging effect was calculated as:

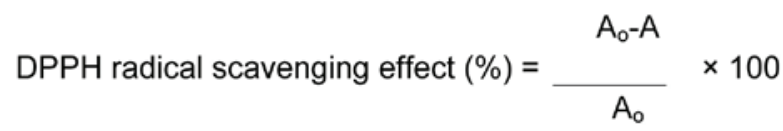

where $A_{o}$ was the absorbance of the control solution (containing only DPPH) and A was the absorbance of DPPH in the sample solution. The determinations were performed in triplicate for each sample and the values were averaged.

To isolate a main active ingredient from FGT, the EtOAc fraction $(5.0 \mathrm{~g})$ was subjected to column chromatography on silica gel eluting with an EtOAc/MeOH gradient (100\% EtOAc to $\mathrm{MeOH}$ ) to afford 16 fractions. Fraction seven, which had markedly higher DPPH radical scavenging activity compared with other fractions, was further separated on silica gel eluting with $\mathrm{CHCl}_{3} / \mathrm{MeOH}$ (10:1) to give compound 1 (30 mg). The structure was identified by nuclear magnetic resonance (NMR) and electron impact mass spectroscopy (EI-MS) and then compared with a commercial sample (Sigma) using high-performance liquid chromatography with a diode array detector (HPLC-DAD).

Pyrogallol (1): White powder; EI-MS m/z $126(\mathrm{M})^{+}$; ${ }^{1} \mathrm{H}-\mathrm{NMR}\left(600 \mathrm{MHz}\right.$; DMSO-d $\left.{ }_{6}\right) \delta, 6.30(2 \mathrm{H} ; \mathrm{d}, J=7.8 \mathrm{~Hz}$; $\mathrm{H}-3,5), 6.47(1 \mathrm{H} ; \mathrm{t}, J=7.8 \mathrm{~Hz} ; \mathrm{H}-4) ;{ }^{13} \mathrm{C}-\mathrm{NMR}(100 \mathrm{MHz}$; DMSO-d $\left._{6}\right) \delta, 134.5(\mathrm{C}-1), 147.7(\mathrm{C}-2,6), 108.5(\mathrm{C}-3,5), 119.8$ (C-4).

XO inhibition assay. The XO inhibition activity was evaluated by the slightly modified method of Parejo et al (20). In this method, $\mathrm{O}_{2}{ }^{--}$reduces a yellow dye, nitroblue tetrazolium $\left(\mathrm{NBT}^{2+}\right)$, to produce blue formazan, which is measured spectrophotometrically at $560 \mathrm{~nm}$.

An assay mixture with a final volume of $150 \mu 1$ was prepared in Eppendorf tubes with $1 \mathrm{mM}$ phosphate buffer (pH 7.4) containing $2 \mathrm{mM}$ xanthine (Sigma), $2 \mathrm{mM} \mathrm{NBT}$ (Sigma) and the respective samples. The reaction was started by adding $0.1 \mathrm{ml} \mathrm{XO}$ (bovine milk origin; Boehringer, Mannheim, Germany) solution in $1 \mathrm{mM}$ phosphate buffer, pH 7.4 (final concentration; $0.0449 \mathrm{U} / \mathrm{ml}$ ) and incubation at $37^{\circ} \mathrm{C}$. Following $20 \mathrm{~min}$, the absorbance was measured at $560 \mathrm{~nm}$.

The results are expressed as the percentage inhibition of the NBT reduction with respect to the reaction mixture without sample (buffer only).

$$
\text { Inhibition (\%) }=1-\frac{\mathrm{S}_{\mathrm{abs}}-\mathrm{SB}_{\text {abs }}}{\mathrm{C}_{\text {abs }}} \times 100
$$

where $\mathrm{S}_{\mathrm{abs}}, \mathrm{SB}_{\mathrm{abs}}$ and $\mathrm{C}_{\mathrm{abs}}$ were the absorbances of the sample, the blank sample and the control, respectively. 
Table I. Total polyphenol contents in GT, FGT and their fractions.

\begin{tabular}{|c|c|c|}
\hline \multirow{2}{*}{ Fraction } & \multicolumn{2}{|c|}{ Total polyphenol contents (mg/g) } \\
\hline & GT & FGT \\
\hline Crude extract & $120.0 \pm 7.9$ & $125.5 \pm 4.6$ \\
\hline EtOAc fraction & $251.4 \pm 21.3$ & $350.9 \pm 10.9^{* * *}$ \\
\hline $\mathrm{BuOH}$ fraction & $213.1 \pm 11.2$ & $219.6 \pm 8.2$ \\
\hline Aqueous fraction & $87.4 \pm 4.3$ & $89.32 \pm 1.0$ \\
\hline
\end{tabular}

GT, Galgeun-tang; FGT, Galgeun-tang fermented with Lactobacillus plantarum; EtOAc, ethyl acetate; $\mathrm{BuOH}$, butanol. Each value is presented as the mean \pm standard deviation $(n=3) .{ }^{*} \mathrm{P}<0.05$, ${ }^{* *} \mathrm{P}<0.01$ compared with GT.

Table II. Total flavonoid contents in GT, FGT and their fractions.

\begin{tabular}{|c|c|c|}
\hline \multirow{2}{*}{ Sample } & \multicolumn{2}{|c|}{ Total flavonoid contents (mg/g) } \\
\hline & GT & FGT \\
\hline Crude extract & $3.05 \pm 0.00$ & $3.79 \pm 0.11^{* *}$ \\
\hline EtOAc fraction & $8.87 \pm 0.35$ & $12.97 \pm 0.84^{* *}$ \\
\hline $\mathrm{BuOH}$ fraction & $5.42 \pm 0.45$ & $6.38 \pm 0.35^{*}$ \\
\hline Aqueous fraction & $1.98 \pm 0.20$ & $1.64 \pm 0.49$ \\
\hline
\end{tabular}

GT, Galgeun-tang; FGT, Galgeun-tang fermented with Lactobacillus plantarum; EtOAc, ethyl acetate; $\mathrm{BuOH}$, butanol. Each value is presented as the mean \pm standard deviation $(n=3) .{ }^{*} \mathrm{P}<0.05$, ${ }^{* *} \mathrm{P}<0.01$ compared with GT.

Table III. Free radical scavenging activities in GT, FGT and their fractions.

\begin{tabular}{lcc}
\hline \multirow{2}{*}{ Sample } & \multicolumn{2}{c}{ DPPH radical scavenging activity (\%) } \\
\cline { 2 - 3 } & GT & FGT \\
\hline Total extract & $22.35 \pm 1.69$ & $27.49 \pm 0.37^{* *}$ \\
EtOAc fraction & $36.95 \pm 2.41$ & $74.17 \pm 4.33^{* *}$ \\
BuOH fraction & $30.97 \pm 0.91$ & $36.32 \pm 1.04^{*}$ \\
Aqueous fraction & $17.00 \pm 2.15$ & $16.34 \pm 1.65$ \\
L-ascorbic acid & \multicolumn{2}{c}{$43.18 \pm 2.40$} \\
\hline
\end{tabular}

GT, Galgeun-tang; FGT, Galgeun-tang fermented with Lactobacillus plantarum; EtOAc, ethyl acetate; $\mathrm{BuOH}$, butanol. The sample concentrations were $500 \mu \mathrm{g} / \mathrm{ml}$. L-(+)-ascorbic acid $(25 \mu \mathrm{g} / \mathrm{ml})$ was used as a positive control. Values are presented as the mean \pm standard deviation $(\mathrm{n}=3) .{ }^{* *} \mathrm{P}<0.01$ and ${ }^{*} \mathrm{P}<0.05$ compared with GT.

HPLC-DAD chemical finger printing of GT and FGT. The Elite LaChrom HPLC-DAD (Hitachi Co., Tokyo, Japan) consisting of a pump (L-2130), autosampler (L-2200), column oven (L-2350) and a diode array ultraviolet-visible (UV-vis)

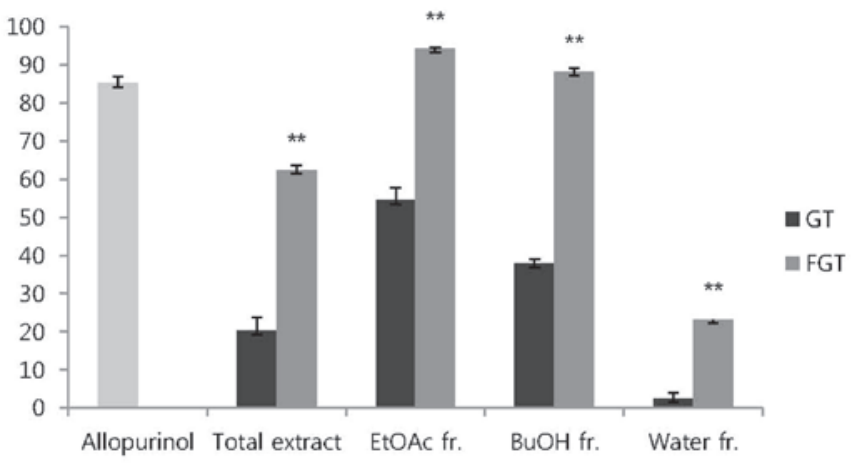

Figure 1. XO inhibition effects of GT and FGT. All the sample concentrations were $500 \mu \mathrm{g} / \mathrm{ml}$. Each value is presented as the mean \pm standard deviation $(\mathrm{n}=3) .{ }^{* *} \mathrm{P}<0.01$ compared with GT. XO, xanthine oxidase; GT, Galgeun-tang; FGT, Galgeun-tang fermented with Lactobacillus plantarum; EtOAc, ethyl acetate; $\mathrm{BuOH}$, butanol; fr., fraction.

light detector (L-2455) was used. An Optima Pak- $\mathrm{C}_{18}$ column (5 $\mu \mathrm{m} ; 100 \AA$; $4.6 \times 250 \mathrm{~mm}$; RStech Corporation, Daedeok, Daejeon, Korea) at $40^{\circ} \mathrm{C}$ was applied for all analyses. The GT and FGT samples were dissolved in $50 \%$ methanol at a concentration of $20 \mathrm{mg} / \mathrm{ml}$. The eluents were A (water) and $\mathrm{B}$ (acetonitrile). The gradient program was used as follows: Initial 0-5 min, A-B (95:5, v/v); 5-70 min, linear change from A-B $(95: 5, v / v)$ to A-B $(0: 100, v / v)$ and then held for $10 \mathrm{~min}$. The re-equilibration duration was $15 \mathrm{~min}$ and aliquots of $10 \mu 1$ were injected.

Statistical analysis. All experiments were performed in triplicate. Data was analyzed using the Student's t-test. $\mathrm{P}<0.05$ was considered to indicate a statistically significant difference.

\section{Results}

Preparation of GT, FGT and their fractions. GT was prepared by extracting Puerariae Radix, Ephedra Herb, Zizyphi Fructus, Cinnamomi Cortex, Paeoniae Radix, Glycyrrhizae Radix and Zingiberis Rhizoma with boiled water. FGT was prepared by fermenting the GT solution with Lactobacillus plantarum. The extraction yields of GT and FGT were 29.4 and $29.6 \%$, respectively.

The solvent fractions of GT and FGT were sequentially partitioned with EtOAc and $\mathrm{BuOH}$ between water. The quantity of organic solvent fraction obtained from FGT (EtOAc, $1.75 \mathrm{~g} ; \mathrm{BuOH}, 4.54 \mathrm{~g}$ ) was higher than that from GT (EtOAc, $0.93 \mathrm{~g} ; \mathrm{BuOH}, 3.82 \mathrm{~g}$ ).

Estimation of total polyphenol and flavonoid contents. The total polyphenol content in the crude extract of FGT (125.5 mg/g) was only slightly higher than that of GT $(120.0 \mathrm{mg} / \mathrm{g})$; however, that of the EtOAc-soluble fraction of FGT $(350.9 \mathrm{mg} / \mathrm{g}$ ) was significantly higher than that of GT (251.4 mg/g) $(\mathrm{P}<0.01$; Table I).

The total flavonoid content of the crude extract of FGT $(3.79 \mathrm{mg} / \mathrm{g})$ was significantly higher than that of GT $(3.05 \mathrm{mg} / \mathrm{g})(\mathrm{P}<0.01)$ and that of the EtOAc-soluble fraction of FGT $(12.97 \mathrm{mg} / \mathrm{g})$ was significantly higher than that of GT $(8.87 \mathrm{mg} / \mathrm{g})(\mathrm{P}<0.01$; Table II). 
A

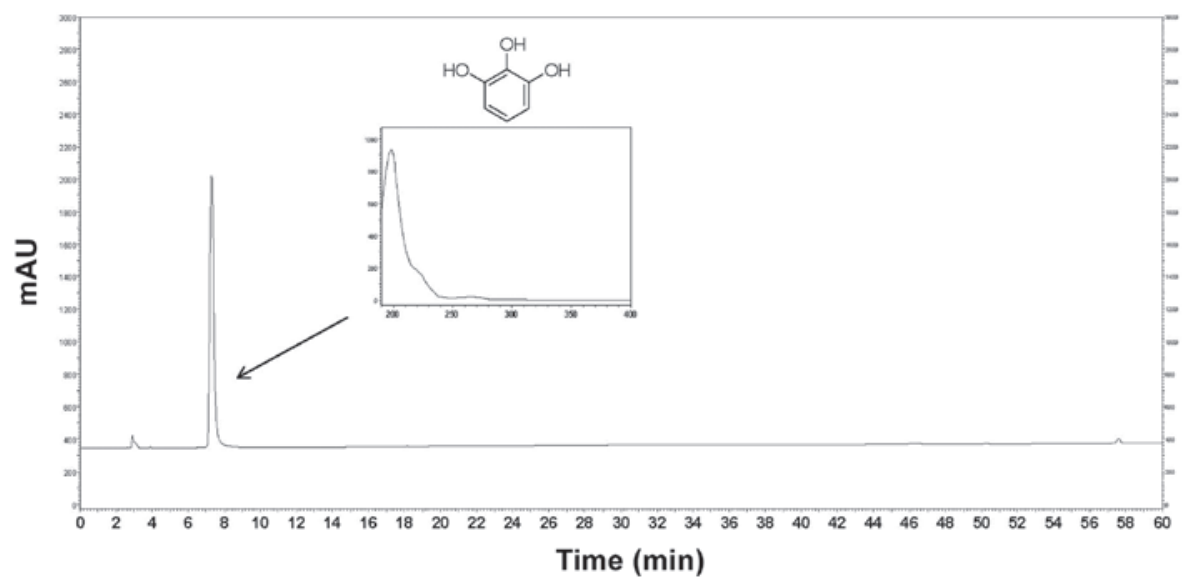

B

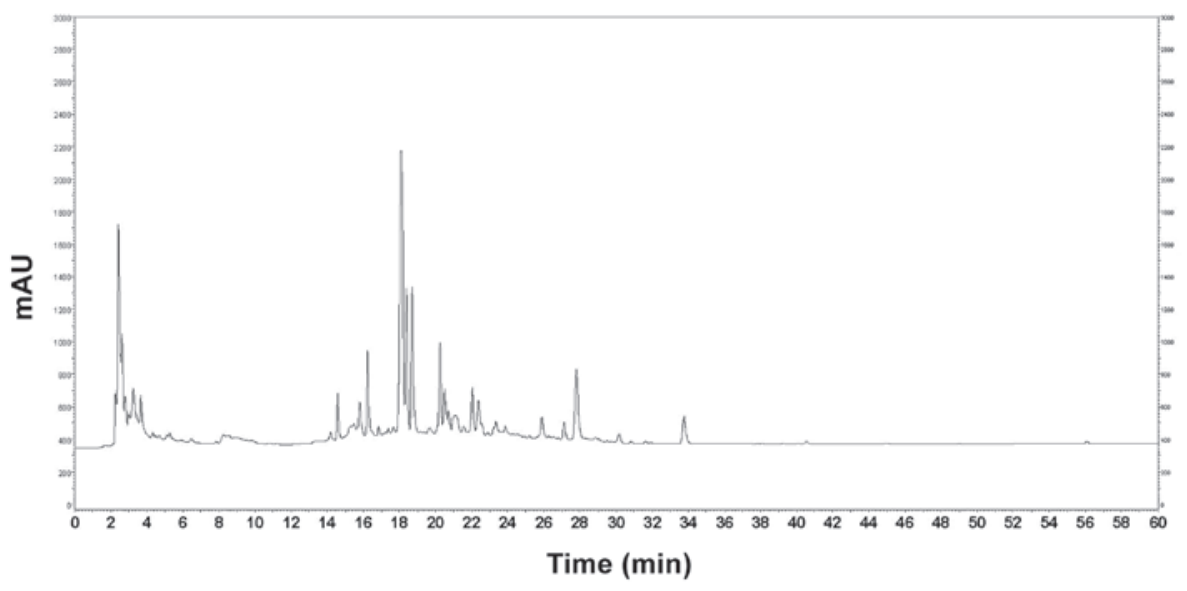

C

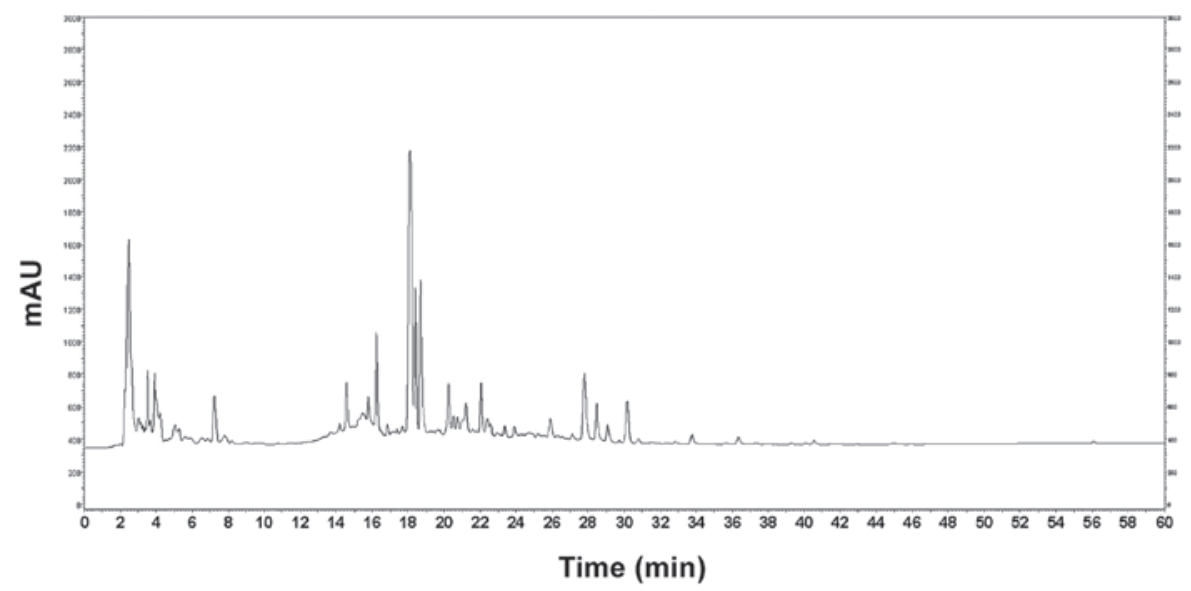

Figure 2. High-performance liquid chromatograms of GT and FGT at $198 \mathrm{~nm}$. (A) Chromatogram of pyrogallol standard; (B) chromatogram of GT; (C) chromatogram of FGT. Retention time was 7.14 min for pyrogallol. GT, Galgeun-tang; FGT, Galgeun-tang fermented with Lactobacillus plantarum.

DPPH radical-scavenging activity and activity-guided fractionation. The DPPH radical scavenging activity of the sample was measured at $500 \mu \mathrm{g} / \mathrm{ml}$. The DPPH radical-scavenging activity of FGT $(27.49 \%)$ was significantly higher than that of GT $(22.35 \%)(\mathrm{P}<0.01)$ and that of the EtOAc-soluble fraction of FGT (74.17\%) was significantly higher than that of GT (36.95\%; Table III). The DPPH radical-scavenging activity of the $\mathrm{BuOH}$-soluble fraction of FGT (36.32\%) was also significantly $(\mathrm{P}<0.05)$ higher than that of the GT $(30.97 \%)$.

Pyrogallol was isolated as the main active ingredient from the EtOAc fraction of FGT. The structure was identified by NMR and MS, and comparison of the spectra with those of authentic commercial samples. The compound produced a strong inhibition of DPPH activity with an $\mathrm{IC}_{50}$ of $12.2 \mu \mathrm{g} / \mathrm{ml}$ as opposed to $29.9 \mu \mathrm{g} / \mathrm{ml}$ for ascorbic acid as a positive reference.

XO inhibition activity. XO inhibitory activities of samples were measured at $500 \mu \mathrm{g} / \mathrm{ml}$. The XO inhibitory activity of the FGT $(62.37 \%)$ was significantly higher than that of GT (20.21\%) (P<0.01; Fig. 1).

The XO inhibitory activities of the solvent-partitioned fractions were higher in the organic solvent-soluble fractions (EtOAc fraction of GT, 54.5\%; EtOAc fraction of FGT, 94.4\%; 
$\mathrm{BuOH}$ fraction of GT, 37.9\%; $\mathrm{BuOH}$ fraction of FGT, $88.2 \%$ ) than in the water-soluble fractions (GT, 2.5\%; FGT, 23.2\%). All the FGT fractions demonstrated significantly higher $\mathrm{XO}$ activities than the GT fractions $(\mathrm{P}<0.05)$.

HPLC-DAD analysis and identification of a major bioconversion component. HPLC-DAD analysis conditions were successfully established for the separation of peaks from GT and FGT (Fig. 2). Numerous increased or decreased peaks at various UV-vis wavelengths were identified. As opposed to GT, pyrogallol was present in FGT at a retention time of $7.14 \mathrm{~min}$.

\section{Discussion}

FGT demonstrated a significantly higher flavonoid content and antioxidant activities than GT. Therefore, FGT is expected to have a stronger biological effect than GT and to also have a longer shelf-life than GT, as antioxidants reduce the oxidation of active substances.

The antioxidant activities as well as the total polyphenol and flavonoid contents in the EtOAc-soluble fractions were markedly increased following fermentation. In addition, the mass of the EtOAc-soluble fraction also increased following fermentation.

These findings suggested that fermentation may have transformed certain components in the herbal decoction into more hydrophobic compounds, possibly increasing the biological effect. Herbal extracts are generally more stable in solid form than in solution. GT is usually administered as a decoction obtained from $25 \mathrm{~g}$ of seven herb materials. From the extraction yield (29.6\%) in the present study, the dried weight was estimated to be $7.4 \mathrm{~g}$, which would equate to $15-20 \mathrm{~g}$ of a tablet, including excipients, and would be inconvenient for intake. If the fermentation process was able to be optimized to increase the biological effect, FGT or its nonpolar fraction may be developed as a solid drug with a lower dosage.

In addition, $\mathrm{XO}$ inhibition activity was highly increased by fermentation. Therefore, according to the present study, FGT or its EtOAc-soluble fraction may be used for further study on the mechanism of action and in vivo efficacies to develop herbal medicines against diseases associated with hyperuricemia.

The potent DPPH radical scavenging activity of pyrogallol has been previously reported (21). Pyrogallol, along with numerous other increased phenolic fermentation products, mainly contributes to the antioxidant activity of FGT. Pyrogallol, which was identified as a major bioconversion component, may be used as a marker compound for the FGT product. The aim of future studies by our group is to identify all the bioconversion components and evaluate other biological activities as well as antioxidant properties.

\section{Acknowledgements}

This study was supported by a grant (no. K11050) from the Korea Institute of Oriental Medicine (Daejeon, Chungnam, Korea).

\section{References}

1. Heo JI: Dong Eui Bo Gam. Namsadang Press, Seoul, pp477, 1976.

2. Montaño A, Casado FJ, de Castro A, Sánchez AH and Rejano L: Vitamin content and amino acid composition of picked garlic processed with and without fermentation. J Agric Food Chem 52: 7324-7330, 2004.

3. LeBlanc JG, Burgess C, Sesma F, Savoy de Giori G and van Sinderen D: Ingestion of milk fermented by genetically modified Lactococus lactis improves the riboflavin status of deficient rats. J Dairy Sci 88: 3435-3442, 2005.

4. Ko YJ, Park SH, Park BC, Lee YH and Kim JA: Fermented ginseng with Bifidobacterium inhibits angiogenesis of human umbilical endothelial cells in vitro and in vivo. Biomol Ther 15: 89-94, 2007.

5. Trinh HT, Han SJ, Kim SW, Lee YC and Kim DH: Bifidus fermentation increase hypolipidemic and hypoglycemic effects of red ginseng. J Microbiol Biotechnol 17: 1127-1133, 2007.

6. Hasegawa $\mathrm{H}$ : Proof of the mysterious efficacy of ginseng: basic and clinical trials: metabolic activation of ginsenoside: deglycosylation by intestinal bacteria and esterification with fatty acid. J Pharmacol Sci 95: 153-157, 2004.

7. You YH, Koh JH, Chung SO, Jun WJ and Kim KM: Effects of fermented Ssanghwatang on swimming capacity in mice. Food Sci Biotechnol 18: 275-277, 2009.

8. Bravo L: Polyphenols: chemistry, dietary sources, metabolism, and nutritional significance. Nutr Rev 56: 317-333, 1998.

9. Kähkönen MP, Hopia AI, Vuorela HJ, Rauha JP, Pihlaja K, Kujala TS and Heinonen M: Antioxidant activity of plant extracts containing phenolic compounds. J Agric Food Chem 47: 3954-3962, 1999.

10. Middleton E Jr, Kandaswami C and Theoharides TC: The effects of plant flavonoids on mammalian cells: implications for inflammation, heart disease, and cancer. Pharmacol Rev 52: 673-751, 2000.

11. Soobrattee MA, Neergheen VS, Luximon-Ramma A, Aruoma OI and Bahorun T: Phenolics as potential antioxidant therapeutic agents: mechanism and actions. Mutat Res 579: 200-213, 2005.

12. Aruoma OI: Free radicals, oxidative stress, and antioxidants in human health and disease. JAOCS 75: 199-212, 1998.

13. Fang J, Seki T and Maeda H: Therapeutic strategies by modulating oxygen stress in cancer and inflammation. Adv Drug Deliv Rev 61: 290-302, 2009.

14. Schmeda-Hirschmann G, Theodoluz C, Franco L, Ferro E and de Arias AR: Preliminary pharmacological studies on Eugenia Uniflora leaves: xanthine oxidase inhibitory activity. J Ethnopharmacol 21: 183-186, 1987.

15. Alderman MH, Cohen H, Madhavan S and Kivlighn S: Serum uric acid and cardiovascular events in successfully treated hypertensive patients. Hypertension 34: 144-150, 1999.

16. Longo-Mbenza B, Luila EL, Mbete P and Vita EK: Is hyperuricemia a risk factor of stroke and coronary heart disease among Africans? Int J Cardiol 71: 17-22, 1999.

17. Kim YS, Lee SJ, Hwang JW, Kim EH, Park PJ and Jeong JH: Antioxidant activities of extracts from Ligustrum ovalifolium H. leaves. J Korean Soc Food Sci Nutr 40: 1642-1647, 2011.

18. Umamaheswari $M$ and Chatterjee TK: In vitro antioxidant activities of the fractions of Coccinia grandis L. leaf extract. Afr J Tradit Complement Altern Med: 61-73, 2007.

19. Hong J, Wie M, Leem D, Park KS, Yoon T, No K and Jeong J: Evaluation of antioxidants activity through the chemical assay. J Biomed Res 11: 1-8, 2010.

20. Parejo I, Viladomat F, Bastida J, Rosas-Romero A, Flerlage N, Burillo L and Codina C: Comparison between the radical scavenging activity and antioxidant activity of six distilled and nondistilled mediterranean herbs and aromatic plants. J Agric Food Chem 50: 6882-6890, 2002.

21. Sroka $Z$ and Cisowski W: Hydrogen peroxide scavenging, antioxidant and anti-radical activity of some phenolic acids. Food Chem Toxicol 41: 753-758, 2003. 